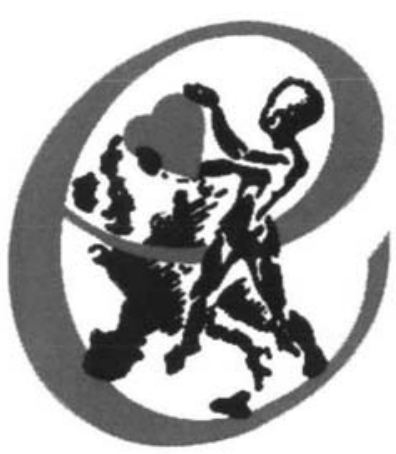

\section{The Association for European Paediatric Cardiology: paediatric cardiology and the European Union}

\author{
Fernando Maymone-Martins
}

President, Association for European Paediatric Cardiology
$\mathrm{P}$ aediatric Cardiology is, by definition, at the cross-roads between General Paediatrics and General Cardiology. This rather obvious statement has acquired special significance in Europe today owing to the development of the European Market and the European Union.

Two aspects play a major role: first, the free movement of persons and goods across national borders and, second, the development of structures at the supra-national level aiming to represent and monitor the delivery of medical care. Harmonisation of training and the need to promote good standards in a heterogeneous Europe become increasingly important. Its implementation relies on the function of some European structures and their articulation with each Country.

Paediatric Cardiology is not fully integrated in General Paediatrics nor in General Cardiology. They both have a voice in the Union of European Medical Specialists. We do not. However, there are some good portents for the future.

The representation of European Paediatric Cardiology through the Association for European Pediatric Cardiology has been beyond dispute for many years, and has been reinforced with the passage of time. The members of the Association already approved in June 1990, in Oslo, the training requirements for Paediatric Cardiology, and decided that it should aim at becoming a monospecialised section within the Union of European Medical Specialists.' In doing so, they clarified the expected level of expertise for the practice of Paediatric Cardiology, and the criteria required for accreditation of training institutions. These matters are within their control, and will be monitored by their representatives.

Although the desired status within the Union of European Medical Specialists has not yet been fully achieved, its level of recognition has increased, and the training requirements have been published off cially by the Union in 1995 in the European Training Charter for Medical Specialists. ${ }^{2,3}$

The Association itself has promoted the role of the National delegates within its own framework. They include countries from outside the European Union, thus ensuring full representation. They are incorporated in a Professional Advisory Committee, which will be responsible for the updating of the requirements for training, and for accreditation of institutions. The promotion of Continuing Medical Education and Evidence Based Medicine are also their concern.

By combining professional activities with the development of scientific activities, and especially by strengthening of the Working Groups, the Association has opened the road towards achieving its main goals. Consequently, the Association enjoys an increasing respect from its partners. In pursuing its objectives, the Association has favoured a good co-operation with the two most closely associated fields: the age-related field of Paediatrics, and the organ-related field of Cardiology.

General Cardiology has shown clear signs of understanding the autonomy of Paediatric Cardiology, namely through the European Society of Cardiology and the European Board for the Speciality of Cardiology. Sometimes, it seems that their counterpart in the field of General Paediatrics, namely the Confederation of European Specialists in Paediatrics, fears the increasing autonomy of the various paediatric specialities. It could be, however, that they ignore the possibility that, by failing to recognise the need for autonomy, the Paediatric specialities could be pushed closer to the adult, organ-related, specialities. In the end, this could be detrimental to good patient care, as the paediatric age group has specific features that 
recommend the maintenance of links and good collaboration among its various constituencies.

In all circumstances, the Association itself will continue as a fully autonomous institution, aiming at the highest possible level of representation. It will be happy to acknowledge the support it may get from its partners in allied fields. We feel that this can only enhance and favour the purpose of mutual collaboration.

The large number of children with heart disease, the particular features of the circulation in childhood and in the fetus, together with the development of new and specific techniques, are constantly serving to reaffirm Paediatric Cardiology as an autonomous field. Establishing the standards, and moving towards their achievement, will eventually lead to full recognition, and thus serve the goals of promoting science and improving the quality of medical care.

\section{References}

1. Daniëls O, Choussat A. Paediatric Cardıology in Europe medical/scientific statement of the Association of European Paediatric Cardiologists. Definition of profession and training requirements. European Heart Journal 1994; 15: 160-163

2. European Training Charter for Medical Specialists. Union Europeenne Des Medcins Specialistes. UEMS 1995; 23-24

3. See the Internet address: users.skynet.be/UEMS/ 